\title{
Platinum-based therapy for triple-negative breast cancer treatment: A meta-analysis
}

\author{
MUYOU TIAN, YAHUA ZHONG, FUXIANG ZHOU, CONGHUA XIE, YUNFENG ZHOU and ZHENGKAI LIAO \\ Department of Radiation Oncology and Medical Oncology, Hubei Cancer Clinical Study Center, Hubei Key Laboratory of \\ Tumor Biological Behaviors, Zhongnan Hospital, Wuhan University, Wuhan, Hubei 430000, P.R. China
}

Received October 15, 2014; Accepted February 13, 2015

DOI: $10.3892 /$ mco.2015.518

\begin{abstract}
The aim of the present study was to evaluate the effect of platinum-based therapy on the short-term efficacy and survival rate in patients with triple-negative breast cancer (TNBC). A search of available databases was conducted, based on specific inclusion and exclusion criteria, for trials conducted between January 2006 and January 2014. The bibliographies of the included studies were examined with the same criteria. Included studies were evaluated using Grading of Recommendations Assessment, Development and Evaluation (GRADE), and extracted data were analyzed using RevMan 5.1 and GRADEprofiler 3.6. Eight studies with a total of 1,349 patients were included. The meta-analysis revealed that the pathological complete response rate and overall response rate in TNBC patients who were treated with a platinum-based regimen was significantly higher than that in those treated with a non-platinum-based regimen (49.2 and $64.3 \%$, respectively). The disease-free survival rate and overall survival rate were not significantly different between TNBC patients treated with a platinum-based regimen and those treated with a non-platinum-based regiment $(\mathrm{P}>0.05)$. Platinum-based chemotherapy in TNBC patients resulted in improved short-term efficacy. Platinum-based regimens may therefore be more sensitive to TNBC patients. However, future multicenter randomized controlled trials are required to validate these findings and to determine whether platinum-based chemotherapy can extend the survival rate of TNBC patients.
\end{abstract}

\section{Introduction}

Triple-negative breast cancer (TNBC) has an estrogen receptor (ER)-negative, progesterone receptor (PR)-negative and

Correspondence to: Dr Zhengkai Liao, Department of Radiation Oncology and Medical Oncology, Hubei Cancer Clinical Study Center, Hubei Key Laboratory of Tumor Biological Behaviors, Zhongnan Hospital, Wuhan University, 169 Donghu Road, Wuhan, Hubei 430000, P.R. China

E-mail: zliao@whu.edu.cn

Key words: triple-negative breast cancer, platinum-based, pathological complete response, overall response rate, survival rate human epidermal growth factor receptor (HER)-2-negative phenotype, and has an aggressive behavior with early visceral metastasis and consequently poorer outcomes (1). Endocrine and HER-2-directed therapy are unsuitable for patients with TNBC, and chemotherapy remains the mainstay of treatment in these cases.

Certain studies of neoadjuvant chemotherapy have suggested that TNBC patients who have a pathological complete response (pCR) to treatment achieve excellent outcomes (2,3). However, the majority of patients with TNBC who receive anthracycline and/or paclitaxel regimens have a lower pCR rate, and for these patients, there is a high risk of relapse and a sharp decrease in the survival rate in the first 3-5 years after treatment. $(4,5)$.

Certain experiments have shown that BRCA1-deficient cells have increased sensitivity to cisplatin (6-8). Cancer cells with a BRCA1 mutation have a defect in the homologous recombination-based repair of double-strand DNA breaks and are sensitive to inter-strand cross-linking agents, such as platinum salts $(7,9,10,11)$. A high proportion of TNBC patients have a BRCA1 functional alteration, and $90 \%$ of tumors carrying a BRCA1 mutation are of the TNBC type (12-14).

Preclinical models and several phase II studies have suggested that platinum-based compounds are active drugs in TNBC, although there have been no randomized studies to support this hypothesis. Patients with BRCA1 mutations receiving cisplatin have pCR rates of $72-83 \%(15,16)$. Therefore, we hypothesized that TNBC may be sensitive to platinum-based regimens. In the present meta-analysis, data were extracted and the overall response rate (ORR) was analyzed for TNBC patients who received a platinum- or non-platinum-based regimen.

\section{Materials and methods}

Literature search strategy. The concept of TNBC was introduced in 2006 (17); therefore, searches of the PubMed database, the China Knowledge Resource Integrated Database, the China Science and Technology Journal Database and the WanFang database were performed using the date limits between January 2006 and June 2014. Studies in Chinese and English were searched. The keywords used were 'platinum-based regimen and triple-negative.' The abstracts of the resulting citations were reviewed, and full-text manuscripts 
were retrieved for the potential studies. In addition, the references of the selected studies were examined for any additional relevant studies.

Literature search strategy. Studies were included in the meta-analysis if the number of TNBC patients treated with a platinum- or a non-platinum-based regimen could be extracted, together with the related data. Studies with incomplete data on the platinum-based regimen, ERs and PRs, and HER2 status were excluded.

Data extraction. Based on the search strategies described above, studies were selected and their eligibility was confirmed by three independent investigators. The following information was extracted from each study: Authors' names, year of publication, study type, the total number of patients and chemotherapy regimens.

Quality evaluation. The collated evidence was evaluated using the Grading of Recommendations Assessment, Development and Evaluation (GRADE) working group framework; accordingly, quality was graded as high, medium, low or extremely low. Randomized controlled trials were considered to be of a high grade, but the following factors were also considered: Risk of bias, inconsistency, indirectness, imprecision and publication bias. Case-control and cohort studies were considered to be of a medium grade.

Statistical analyses. Meta-analysis was conducted using Review Manager software (RevMan, version 5.1 for Windows; Cochrane Collaboration, Oxford, UK). The odds ratio (OR) and $95 \%$ confidence interval $(95 \% \mathrm{CI})$ were calculated. A $\chi^{2}$ test was used to evaluate heterogeneity in the data. The fixed-effects model was used for studies without significant heterogeneity $\left(\mathrm{I}^{2} \leq 50 \%\right.$ or $\left.\mathrm{P} \geq 0.1\right)$, whereas the random-effects model was used for studies with significant heterogeneity. Funnel plots were generated using RevMan to detect publication bias. Quality evaluation was conducted using GRADEpro software (version 3.6 for Windows; Cochrane Collaboration). A paired sample t-test was analyzed using SPSS (version 19; IBM Corp., Armonk, NY, USA).

\section{Results}

Eligible studies and data summary. A total of 248 studies were first identified for evaluation. Based on the criteria described, 8 publications with 1,349 patients were eligible for inclusion in the meta-analysis. The search process is described in Fig. 1, and more details are provided in Table I.

$p C R$ rate and $O R R$ of TNBC patients treated with a platinum- or non-platinum-based regimen. Four studies (18-21) reported the pCR rate and five studies $(18,21-24)$ reported the ORR in TNBC patients who were treated with a platinum- or a non-platinum-based regimen. There was significant heterogeneity between different study results $\left(\mathrm{I}^{2}>50 \%, \mathrm{P}<0.1\right)$, so the random-effects model was applied for data analysis. The pCR rate in TNBC patients who were treated with a platinum-based regimen was significantly higher than that in those treated with a non-platinum-based

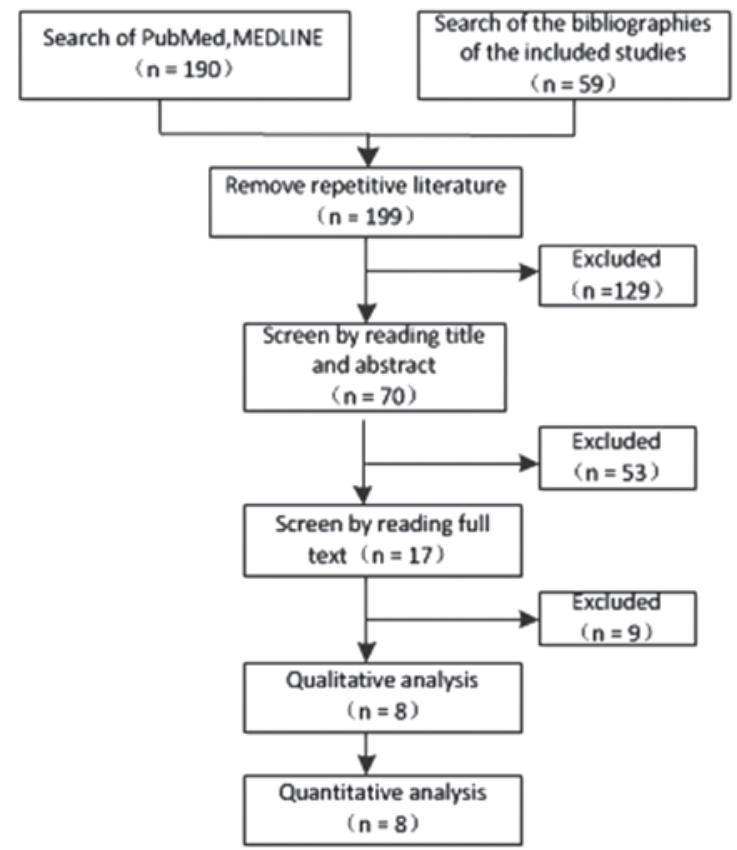

Figure 1. Flow-chart of the literature search process.

regimen (49.2 vs. 36.9\%; OR, 1.66; 95\% CI, 1.05-2.64; Fig. 2). The ORR in TNBC patients who were treated with a platinum-based regimen was significantly higher than that in those treated with a non-platinum-based regimen (64.3 vs. 42.5\%; OR, 2.33; 95\% CI, 1.23-4.40; Fig. 3).

Survival rate of TNBC patients treated with a platinum-or non-platinum-based regimen. Four studies (22-25) reported that the overall survival (OS) rate was not significantly different between TNBC patients treated with a platinum-based regimen and those treated with a non-platinum-based regimen ( $\mathrm{P}>0.05)$. So does the disease-free survival (DFS) rate according to three studies (Table II) (22-24).

Quality evaluation. The quality of the meta-analysis was evaluated using the GRADE framework and is shown in Table III. The assessment was considered to be of moderate quality. Moderate between-study heterogeneity was present for the risk difference analysis. Funnel plots for risk ratio and risk difference showed mild asymmetry, indicating certain publication bias (Figs. 4 and 5).

\section{Discussion}

The present study showed that TNBC patients treated with a platinum-based regimen had a higher $\mathrm{pCR}$ rate and ORR. There was no significant increase in the OS and DFS, but due to the few studies included this may be disregarded. Anthracycline and paclitaxel are the common non-platinum-based regimens; however, they result in only a low pCR rate $(2,3)$. Patients with TNBC who achieved a pCR usually have an improved outcome, and thus combining a platinum-based regimen in treatment may be of significant benefit. However, more trials are required to fully evaluate the survival rate of TNBC patients receiving platinum-based regimens. 
Table I. Characteristics of the eligible studies.

\begin{tabular}{|c|c|c|c|c|c|}
\hline First author (Ref) & Year & Country & Type & Platinum-based regimen & Nonplatinum regimen \\
\hline Fan (22) & 2013 & China & Phase II clinical trial & Docetaxel plus cisplatin for 6 cycles & $\begin{array}{l}\text { Docetaxel plus capecitabine for } \\
6 \text { cycles }\end{array}$ \\
\hline Bhattacharyya (7) & 2009 & / & Phase II clinical trial & $\begin{array}{l}\text { Cyclophosphamide plus methotrexate } \\
\text { plus cisplatin }\end{array}$ & $\begin{array}{l}\text { Cyclophosphamide plus } \\
\text { methotrexate }\end{array}$ \\
\hline $\mathrm{Wu}(23)$ & 2012 & China & Retrospective analysis & $\begin{array}{l}\text { TP (paclitaxel+Platinum), } \\
\text { NP (vinorelbine+Platinum), } \\
\text { GP (gemcitabine+ Platinum) }\end{array}$ & $\begin{array}{l}\text { AT (antharcycline+paclitaxel), } \\
\text { TX (paclitaxel+capecitabin }\end{array}$ \\
\hline Alba (18) & 2012 & Spain & Phase II clinical trial & $\begin{array}{l}\text { EC-DCb: EC (epirubicin plus } \\
\text { for } 4 \text { cycles) followed } \\
\text { by DCb (docetaxel plus } \\
\text { carboplatin AUC } 6 \text { for } 4 \text { cycles) }\end{array}$ & $\begin{array}{l}\text { EC-D: EC (epirubicin plus } \\
\text { cyclophosphamide for } 4 \text { cycles) } \\
\text { followed by D (docetaxel for } \\
4 \text { cycles) }\end{array}$ \\
\hline $\begin{array}{l}\text { Villarreal- } \\
\text { Garza (25) }\end{array}$ & 2014 & Canada & Retrospective analysis & $\begin{array}{l}\text { TP (paclitaxel+Platinum), } \\
\text { NP (vinorelbine+Platinum), } \\
\text { GP (gemcitabine+Platinum) }\end{array}$ & Not given \\
\hline von Minckwitz (19) & 2014 & Germany & Phase II clinical trial & $\begin{array}{l}\text { Carboplatin (AUC } 1.5-2.0 \text { ) plus } \\
\text { paclitaxel plus non-pegylated liposomal } \\
\text { doxorubicin plus bevacizumab }\end{array}$ & $\begin{array}{l}\text { Paclitaxel plus non-pegylated } \\
\text { liposomal doxorubicin plus } \\
\text { bevacizumab }\end{array}$ \\
\hline Sikov (20) & 2015 & America & Phase II clinical trial & $\begin{array}{l}\text { Carboplatin (AUC 6) plus paclitaxel plus } \\
\text { doxorubicin plus cyclophosphamide for } \\
4 \text { cycles with or without bevacizumab } \\
\text { for } 9 \text { cycles }\end{array}$ & $\begin{array}{l}\text { Paclitaxel plus doxorubicin plus } \\
\text { cyclophosphamide for } 4 \text { cycles with } \\
\text { or without bevacizumab for } 9 \text { cycles }\end{array}$ \\
\hline Zhang (21) & 2013 & China & Phase II clinical trial & $\begin{array}{l}\text { Paclitaxel plus carboplatin (AUC 5) for } \\
4-6 \text { cycles }\end{array}$ & $\begin{array}{l}\text { Epirubicin plus paclitaxel for } \\
4-6 \text { cycles }\end{array}$ \\
\hline
\end{tabular}

AUC, area under the curve.

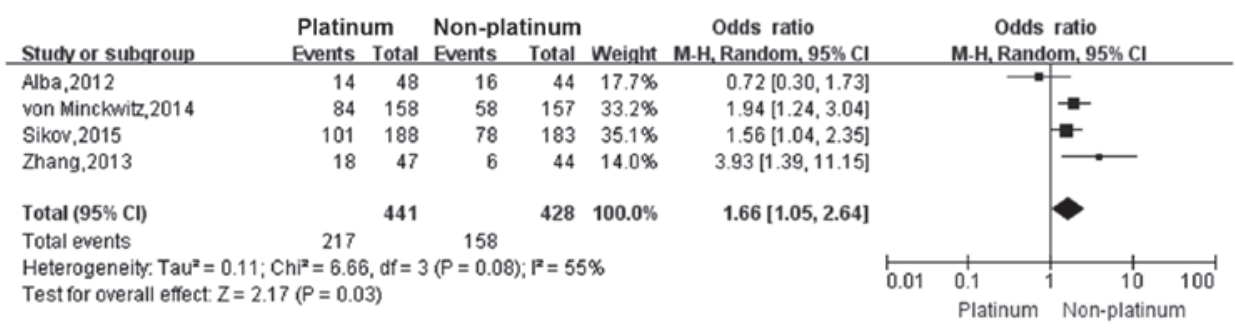

Figure 2. Forest plot of the pCR rate in TNBC patients who were treated with a platinum- or non-platinum-based regimen. pCR, pathological complete response.

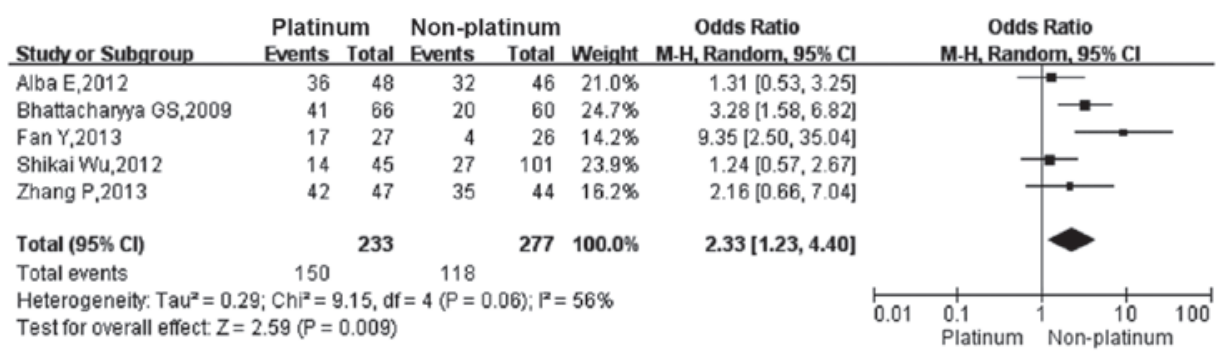

Figure 3. Forest plot of the ORR in TNBC patients who were treated with a platinum- or non-platinum-based regimen. ORR, overall response rate.

Previous studies have shown that mutations in the BRCA1 gene are prevalent in TNBC tumors, and certain preclinical studies showed that TNBC cell lines are more sensitive to DNA-damaging agents, such as platinum compounds $(7,8)$. There is also evidence for a dysfunctional BRCA1 pathway in sporadic TNBC (26). Previously, it has been reported that cisplatin selectively induces cell death in TNBC cells through a mechanism involving the p53 family members, p63 and p73 (27).

Platinum-based chemotherapy appears to be effective in a high proportion of patients with mutant BRCAl-associated 
Table II. Disease-free survival (DFS) and overall survival (OS) rates in studies of triple-negative breast cancer patients who were treated with a platinum- or non-platinum-based regimen.

\begin{tabular}{lccccccrrr}
\hline & \multicolumn{3}{c}{ OS, months } & & P-value & & DFS, months & P-value \\
\hline Platinum-based regimen & 32.8 & 24.9 & 16.0 & 14.5 & $>0.05$ & 10.9 & 2.8 & 13.0 & $>0.05$ \\
Non-platinum-based regimen & 21.5 & 26.3 & 12.0 & 10.0 & & 4.8 & 3.0 & 7.0 \\
\hline
\end{tabular}

Table III. GRADE framework assessment of eligible studies.

\begin{tabular}{|c|c|c|c|c|c|c|c|c|}
\hline \multirow[b]{2}{*}{ Outcome } & \multicolumn{2}{|c|}{ Design } & \multicolumn{4}{|c|}{ Quality assessment } & \multirow{2}{*}{$\begin{array}{l}\text { No. of } \\
\text { eligible } \\
\text { studies }\end{array}$} & \multirow[b]{2}{*}{ Quality } \\
\hline & Experiment & Control & Risk of bias & Inconsistency & Indirectness & Imprecision & & \\
\hline $\mathrm{pCR}$ & $\begin{array}{l}\text { Platinum-based } \\
\text { regimen }\end{array}$ & $\begin{array}{l}\text { Non-platinum } \\
\text { regimen }\end{array}$ & Serious & $\begin{array}{l}\text { No serious } \\
\text { inconsistency }\end{array}$ & $\begin{array}{l}\text { No serious } \\
\text { indirectness }\end{array}$ & $\begin{array}{l}\text { No serious } \\
\text { imprecision }\end{array}$ & 5 & Moderate \\
\hline ORR & $\begin{array}{l}\text { Platinum-based } \\
\text { regimen }\end{array}$ & $\begin{array}{l}\text { Platinum-based } \\
\text { regimen }\end{array}$ & Serious & $\begin{array}{l}\text { No serious } \\
\text { inconsistency }\end{array}$ & $\begin{array}{l}\text { No serious } \\
\text { indirectness }\end{array}$ & $\begin{array}{l}\text { No serious } \\
\text { imprecision }\end{array}$ & 4 & Moderate \\
\hline
\end{tabular}

GRADE, Grading of Recommendations Assessment, Development and Evaluation; pCR, pCR, pathological complete response; ORR, overall response rate.

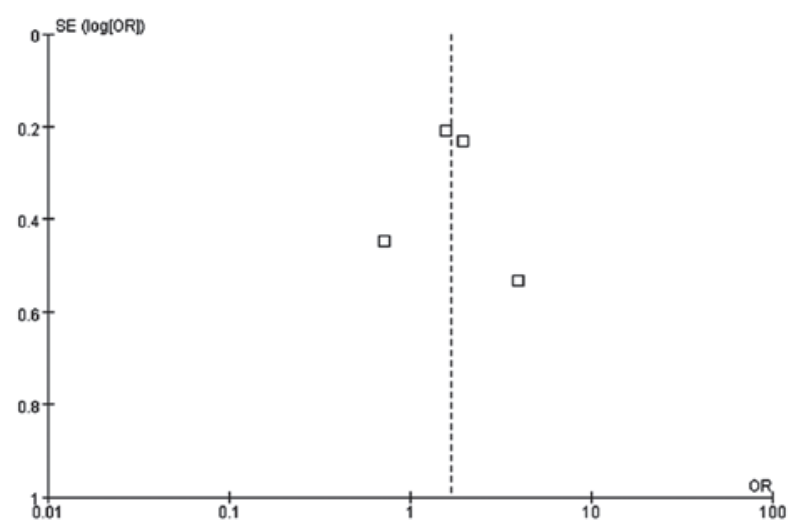

Figure 4. Funnel plot of the pCR rate in TNBC patients who were treated with a platinum- or non-platinum-based regimen. pCR, pathological complete response.

breast cancers. A pCR rate of $72 \%$ following neoadjuvant cisplatin treatment in 25 patients carrying the BRCAl mutation was reported (16), and a high proportion (83\%) of females with $B R C A 1$-associated breast cancer responded to platinum-based chemotherapy in a study conducted in Poland (15). Furthermore, TNBC patients with high-risk features are 5.6 times more likely to carry a BRCA1 mutation compared to patients with a non-TNBC tumor, and approximately two in nine females with TNBC harbor a BRCAl mutation (28). Platinum-based neoadjuvant chemotherapy in TNBC patients resulted in improved short-term efficacy compared to its use in non-TNBC patients, but it has not yet been demonstrated to improve efficacy in advanced breast cancer (29).

There are certain relevant ongoing clinical trials, including a randomized phase III trial comparing the efficacy of carboplatin to docetaxel for patients with advanced TNBC (30). Another trial is currently underway to assess the efficacy of platinum-based therapy for metastatic TNBC, and evaluating the use of p63/p73 as a biomarker of response (31).

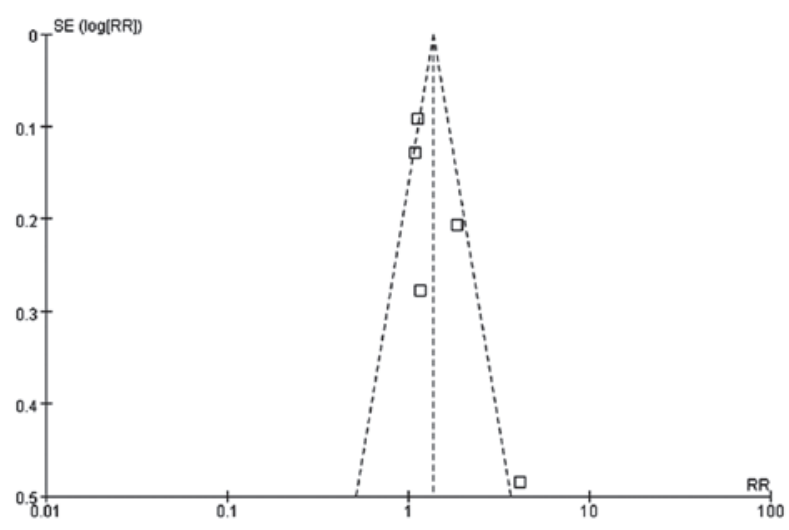

Figure 5. Funnel plot of the ORR in TNBC patients who were treated with a platinum- or non-platinum-based regimen. ORR, overall response rate.

All the patients included in the present meta-analysis had either newly diagnosed or relapsed disease. Therefore, it is possible that ambiguity in the actual cancer stage could have introduced a bias in the data; however, the quality of these studies was mostly considered to be moderate. In general, the overall results were reliable despite certain publication bias.

In conclusion, platinum-based chemotherapy in TNBC patients resulted in an improved short-term efficacy compared to the non-platinum-based regimen group. Platinum-based therapy is more effective to triple-negative breast cancer. Future multicenter randomized controlled trials are required to validate these findings and to determine whether platinum-based chemotherapy can extend the survival rate of TNBC patients.

\section{Acknowledgements}

The present study is supported by the programmefor the National Natural Science Foundation of China (grant no. 30800278) 
and Doctoral Fund of Ministry of Education of China (Youth Scholars) (grant no. 200804861048) to Dr Liao.

\section{References}

1. Reis-Filho JS and Tutt AN: Triple negative tumours: a critical review. Histopathology 52: 108-118, 2008.

2. Masuda H, Masuda N, Kodama Y, et al: Predictive factors for the effectiveness of neoadjuvant chemotherapy and prognosis in triple-negative breast cancer patients. Cancer Chemother Pharmacol 67: 911-917, 2011.

3. Chang HR, Glaspy J, Allison MA, et al: Differential response of triple-negative breast cancer to a docetaxel and carboplatin-based neoadjuvant treatment. Cancer 116: 4227-4237, 2010.

4. Cheang MC, Voduc D, Bajdik C, et al: Basal-like breast cancer defined by five biomarkers has superior prognostic value than triple-negative phenotype. Clin Cancer Res 14: 1368-1376, 2008.

5. Dent R, Trudeau M, Pritchard KI, et al: Triple-negative breast cancer: clinical features and patterns of recurrence. Clin Cancer Res 13: 4429-4434, 2007.

6. Tassone P, Di Martino MT, Ventura M, et al: Loss of BRCA1 function increases the antitumor activity of cisplatin against human breast cancer xenografts in vivo. Cancer Biol Ther 8: 648-653, 2009.

7. Bhattacharyya A, Ear US, Koller BH, Weichselbaum RR and Bishop DK: The breast cancer susceptibility gene BRCA1 is required for subnuclear assembly of Rad51 and survival following treatment with the DNA cross-linking agent cisplatin. J Biol Chem 275: 23899-23903, 2000

8. Quinn JE, Kennedy RD, Mullan PB, et al: BRCA1 functions as a differential modulator of chemotherapy-induced apoptosis. Cancer Res 63: 6221-6228, 2003

9. Kennedy RD, Quinn JE, Mullan PB, Johnston PG and Harkin DP: The role of BRCA1 in the cellular response to chemotherapy. J Natl Cancer Inst 96: 1659-1668, 2004

10. Moynahan ME, Chiu JW, Koller BH and Jasin M: Brca1 controls homology-directed DNA repair. Mol Cell 4: 511-518, 1999.

11. Rodler E, Korde L and Gralow J: Current treatment options in triple negative breast cancer. Breast Dis 32: 99-122, 2010.

12. Chacón RD and Costanzo MV: Triple-negative breast cancer. Breast Cancer Res 12 Suppl 2: 3, 2010.

13. Andre F and Zielinski CC: Optimal strategies for the treatment of metastatic triple-negative breast cancer with currently approved agents. Ann Oncol 23 Suppl 6: vi46-vi51, 2012.

14. Foulkes WD, Smith IE and Reis-Filho JS: Triple-negative breast cancer. N Engl J Med 363: 1938-1948, 2010.

15. Byrski T, Gronwald J, Huzarski T, et al: Pathologic complete response rates in young women with BRCA1-positive breast cancers after neoadjuvant chemotherapy. J Clin Oncol 28: 375-379, 2010.

16. Byrski T, Huzarski T, Dent R, et al: Response to neoadjuvant therapy with cisplatin in BRCA1-positive breast cancer patients. Breast Cancer Res Treat 115: 359-363, 2009.

17. Livasy CA, Perou CM, Karaca G, et al: Identification of a basal-like subtype of breast ductal carcinoma in situ. Hum Pathol 38: 197-204, 2007.
18. Alba E, Chacon JI, Lluch A, et al: A randomized phase II trial of platinum salts in basal-like breast cancer patients in the neoadjuvant setting. Results from the GEICAM/2006-03, multicenter study. Breast Cancer Res Treat 136: 487-493, 2012.

19. von Minckwitz G, Schneeweiss A, Loibl S, Salat C, Denkert C, Rezai M, et al: Neoadjuvant carboplatin in patients with triple-negative and HER2-positive early breast cancer (geparsixto; GBG 66): a randomised phase 2 trial. Lancet Oncol 15: 747-756, 2014.

20. Sikov WM, Berry DA, Perou CM, et al: Impact of the addition of carboplatin and/or bevacizumab to neoadjuvant once-per-week paclitaxel followed by dose-dense doxorubicin and cyclophosphamide on pathologic complete response rates in stage II to III triple-negative breast cancer: CALGB 40603 (alliance). J Clin Oncol 33: 13-21, 2015.

21. Zhang P, Yin Y, Xu B, et al: Carboplatin plus paclitaxel compared with epirubicin plus paclitaxel as neoadjuvant chemotherapy for triple-negative breast cancer - a phase II clinical trial. Cancer Res 73: P3-14-07, 2013.

22. Fan Y, Xu BH, Yuan P, et al: Docetaxel-cisplatin might be superior to docetaxel-capecitabine in the first-line treatment of metastatic triple-negative breast cancer. Ann Oncol 24: 1219-1225, 2013.

23. Wu SK, Zhao X, Meng XY, et al: Analysis of chemotherapeutic efficacies in metastatic triple-negative breast cancer. Zhonghua Yi Xue Za Zhi 13: 3001-3003, 2012.

24. Bhattacharyya GS, Basu S, Agarwal V, et al: Single institute phase ii study of weekly cisplatinum and metronomic dosing of cyclophosphamide and methotrexate in second line metastatic breast cancer triple-negative. Eur J Cancer (Abstr 41LBA, presented data-ECCO 15-ESMO 34 2009) 7: 2009.

25. Villarreal-Garza C, Khalaf D, Bouganim N, Clemons $M$, Pena-Curiel O, Baez-Revueltas B, et al: Platinum-based chemotherapy in triple-negative advanced breast cancer. Breast Cancer Res Treat 146: 567-572, 2014

26. Turner NC, Reis-Filho JS, Russell AM, et al: BRCA1 dysfunction in sporadic basal-like breast cancer. Oncogene 26: 2126-2132, 2007.

27. Leong CO, Vidnovic N, DeYoung MP, Sgroi D and Ellisen LW: The p63/p73 network mediates chemosensitivity to cisplatin in a biologically defined subset of primary breast cancers. J Clin Invest 117: 1370-1380, 2007.

28. Tun NM, Villani G, Ong K, Yoe L and Bo ZM: Risk of having BRCA1 mutation in high-risk women with triple-negative breast cancer: a meta-analysis. Clin Genet 85: 43-48, 2014.

29. Liu M, Mo QG, Wei CY, Qin QH, Huang Z and He J: Platinum-based chemotherapy in triple-negative breast cancer: a meta-analysis. Oncol Lett 5: 983-991, 2013.

30. ISRCTN Registry: Triple Negative Trial: a randomised phase III trial of carboplatin compared to docetaxel for patients with advanced oestrogen receptor-progesterone receptor-human epidermal growth factor receptor two-breast cancer. www.isrctn. com/ISRCTN97330959. Accessed July 4, 2014.

31. ClinicalTrials.gov: Platinum for triple-negative metastatic breast cancer and evaluation of $\mathrm{p} 63 / \mathrm{p} 73$ as a biomarker of response. https://clinicaltrials.gov/ct2/show/NCT00483223. Accessed July 4, 2014. 